resins and many other special classes. In each of these fields special procedures for physical and chemical analysis have been developed and their description is widely scattered throughout the literature, in industrial specifications and in research reports.

This book, which is the collective work of twentysix authors who are all members of the staff of American industrial concerns, brings together in one volume methods of analysis which have been used successfully in the determination and testing of commercial monomers and polymers. The methods for the determination of physical properties and chemical composition of each of the major industrial polymers, namely, acrylic plastics, alkyls, aminoresins, cellulose derivatives, epoxy resins, ethylene and fluoroethylene polymers, furan resins, natural resins, phenolic resins, polyamides, polyesters, proteins, rubbers (natural and synthetic), silicones, styrene monomers and polymers, vinyl polymers and co-polymers, and synthetic and natural fibres, are summarized in a separate chapter.

In each case methods are described for the assay and determination of pertinent impurities in the monomers; this is followed by a discussion of analytical problems of identification and characterization of the chemical composition and physical properties of the polymers. Special chapters are devoted to plasticizers, ion-exchange resins and drying oils. In general, the main features of the analytical method and apparatus used are described and the reader is referred to the original publication for detailed directions. In cases where the methods have not been previously published, full details of the procedure are given.

The book provides the best survey and compilation I have seen, and it should be of great use to the practising polymer chemist and analyst. The editor has been successful in bringing together a very valuable collection of information on polymers, and in the second volume, which is in preparation, it is intended to cover the subjects of molecular structure determination, chemical group analysis and identification procedures for polymers.

C. E. H. BAwN

\section{THE ORGANIC CHEMISTRY OF SULPHUR}

Aspects of the Organic Chemistry of Sulphur By Prof. Frederick Challenger. (Organic Chemistry Monographs.) Pp. vii +253. (London: Butterworths Scientific Publications ; New York : Academic Press, Inc., 1959.) 40s. ; 7.50 dollars.

A CONSIDERABLE portion of Prof. F. Challenger's researches have been concerned with organic derivatives of sulphur, and a book on this subject written by him is greatly welcome. He has chosen six topics to discuss, each as a separate chapter, and naturally occurring organic derivatives occupy a prominent position. Many of the subjects discussed are those which he has studied intensively in the course of his own work, and upon which he can therefore write with particular authority.

The first two chapters, on "Simple Organic Compounds of Sulphur. Properties, Preparation and Biological Significance" and "Natural Sulphonium Compounds, Sulphides, Sulphoxides, Mercaptans and
Sulphido-amino Acids" respectively, cover appropriately the widest fields, but even in discussing these comparatively simple classes of compounds the author has a fund of very interesting information on various points which will probably be novel to many organic chemists.

The chapter on "Sulphur Compounds of Petroleum" affords an excellent account of this subject, and the discussion of the desulphurization of organic compounds by Raney nickel, its mechanism, stereochemistry, and various applications is of great value.

Each of the remaining three chapters forms a complete monograph in itself. "The Natural Mustard Oil Glucosides and the Related Isothiocyanates and Nitriles" starts with a very interesting historical review of the early work on oil of mustard, and then covers the modern chemistry of a surprisingly wide variety of compounds in its 146 pages. Prof. Challenger has worked on biological methylation since 1931, and his chapter "Biological Methylation with Particular Reference to Compounds of Sulphur" gives, as one would expect, an authoritative and thoroughly comprehensive account of this subject. Among the many subjects discussed are the mechanism of biological methylation, the transmethylation from methionine and choline, and the formation of 'active methionine' in enzyme systems and its synthesis in the laboratory : the chapter finishes with a discussion of the metabolism of ethanethiol, and the possible mechanism of its anti-tubercular effect. The last chapter is devoted to "Co-enzyme A, its S-acetyl Derivative and Related Compounds."

One quality of this book which greatly impressed me is that it is refreshingly readable. This arises partly from the author's clear natural style, and partly from his gift of presenting and discussing a considerable amount of material in a deceptively unhurried manner, so that, although no words are wasted, the reader never feels that he is being 'crowded'.

This high standard of writing, combined with the author's wide knowledge, makes one wish that he would now, with greater leisure, write a volume which would be the sulphur analogue of Sidgwick's "Nitrogen", that is, a volume in which the preparation and properties of the various classes of organic sulphur compounds would be systematically discussed, and many features of their chemistry critically assessed, without any attempt to achieve a comprehensive account. Several chemists have started on this task, and have fallen by the wayside en route: Prof. Challenger's vigour and enthusiasm would take him safely-and still in eminently readable style-to the end of the task.

F. G. MANN

\section{LIGHT-INITIATED ORGANIC SYNTHESIS}

Präparative Organische Photochemie

Von Prof. Alexander Schönberg. (Organische Chemie in Einzeldarstellungen, Band 6.) Pp. xii +274 . (Berlin : Springer-Verlag, 1958.) 58 D.M.

DHOTOCHEMISTRY is perhaps still considered to be essentially the province of the physical chemist, yet during the past twenty-five years a vast amount of information has accumulated on the use of light to initiate reactions leading to the formation of relatively simple organic molecules (as distinct from polymers of high molecular weight). Prof. A. Schönberg 